\title{
К ВОПРОСУ УПРАВЛЕНИЯ АКТИВАМИ В СОВРЕМЕННЫХ УСЛОВИЯХ
}

\author{
(c) 2021 Вишневер Вадим Яковлевич \\ кандидат экономических наук, доцент кафедры «Экономическая теория» \\ Самарский государственный экономический университет (СГЭУ), Самара, Россия \\ E-mail: ab3535@mail.ru
}

В статье рассматривается проблема управления активами в целях их наиболее эффективного инвестирования. Выявляются отличительные особенности индивидуального и коллективного управления активами, их положительные и отрицательные стороны. Дан анализ рынка доверительного управления и коллективного инвестирования в РФ за 2019-2020 гг.

Ключевые слова: доверительное управление, управление активами, управляющие компании, особенности доверительного управления, принципы доверительного управления, рынок доверительного управления и коллективного инвестирования в РФ.

Российский рынок ценных бумаг во многом носит спекулятивный характер, что показывает его отрыв от потребностей реального сектора экономики. Необходимо переориентировать рынок ценных бумаг в России преимущественно от спекулятивного направления к инвестиционному. Это может быть достигнуто с помощью использования инструментов индивидуального и коллективного инвестирования и рынка доверительного управления [1].

Для того чтобы наиболее эффективно использовать свои свободные денежные средства, инвестор может не только вкладывать активы в финансовые инструменты самостоятельно, но и передавать их управляющей компании для наиболее эффективного инвестирования.

Управляющие компании (УК) - профессиональные участники фондового рынка, которые осуществляют посредническую деятельность по доверительному управлению активами по поручению и в интересах своих клиентов.

УК, как правило, обеспечивают более высокие результаты управления активами. Также в связи с тем, что объем активов в управлении достаточно емкий, затраты, связанные с операциями на рынке ценных бумаг минимальны. Управляющие компании осуществляют сделки одновременно на разных рынках и в разных секторах рынка, что обеспечивает эффективность такого управления [2].

Для реализации возможности передачи управления имуществом инвестора профессиональной управляющей компании необходимо заключение Договора доверительного управления (ДУ). В соответствии с договором учредитель управления передает свои активы (денежные средства, ценные бумаги и другие активы) на определенный срок доверительного управления.

УК, в отличие от такого участника рынка ценных бумаг как брокер, вправе самостоятельно принимать различные решения по сделкам с активами, однако ее действия не должны противоречить той инвестиционной стратегии, которую они подобрали вместе с клиентом (учредителем). Все действия УК направлены на приращение доходов учредителя.

Инвестиционные решение необходимо принимать, учитывая следующие моменты:

- надежность вложений;

- рискованность активов;

- сумма, которая может быть передана в управление.

Частный инвестор может выбрать коллективное, либо индивидуальное управление своими средствами. Коллективное управление предполагает объединение средств клиентов в общую сумму и создание «пула» для управления. В этом типе управления клиент имеет возможность предоставить минимальную сумму для управления и выбрать оптимальные стратегии.

Коллективное управление обычно осуществляется в форме паевого инвестиционного фонда. Обычно из средств учредителей собирается некий имущественный комплекс (ПИФ), который впоследствии передается в УК. На свою долю (пай), каждый инвестор получает соответствующий доход. Таким образом, коллективное управление - это форма доверительного управления доступная мелким инвесторам [3].

Положительные стороны коллективного до- 
верительного управления:

- Более низкий входной барьер (средняя стоимость пая инвестора может составлять несколько тысяч рублей). Это дает возможность доверить активы профессионалам при небольших суммах инвестирования.

- Ограниченные риски, за счет заключения инвестиционной декларации.

- Широкий выбор инструментов инвестирования. В этом случае инвестор может выбрать конкретный сегмент рынка или тип актива.

Отрицательные стороны коллективного доверительного управления:

- Индивидуального подхода к инвестициям нет, каждый инвестор должен принять общую инвестиционную стратегию.

- Инвестор не имеет постоянной возможности отслеживать состояние портфеля, как при самостоятельном инвестировании. Он получает лишь периодические отчеты о результатах управления и структуре активов.

- Нередко управляющие компании сдерживает законодательство в отношении состава, структуры активов и типов проводимых операций.

- Фиксированная комиссия в виде платы за покупку или продажу пая, а также фиксированный процент от размера портфеля в течение года. Такой метод вознаграждения дает недостаточную мотивацию управляющей компании для обеспечения максимальной доходности.

В отличие от паевых инвестиционных фондов, при индивидуальном доверительном управлении управление активами персонифицировано. Здесь может использоваться абсолютно любая инвестиционная стратегия, от классических пассивных стратегий до спекулятивных с использованием роботов, алгоритмов и т.д. Инвестирование может происходить в любые активы как срочного рынка, так и рынка спот, а также на зарубежных торговых площадках.

Под индивидуальным управлением понимается управление активами одного учредителя. Для формирования собственного инвестиционного портфеля, инвестору необходимо обладать достаточным количеством активов, так как порог вхождения весьма высок. Портфель формируется из ряда финансовых активов на основе соотношения возможной доходности и приемлемой рискованности.

Отличительной особенностью индивидуального ДУ (ИДУ) от коллективного является экс- клюзивность предоставляемых услуг и способ выведения активов из ДУ.

Положительные стороны индивидуального доверительного управления:

- Персонализированный подход к инвестиционным целям клиента и разработка индивидуальных методов их достижения.

- Реализация различных инвестиционных стратегий, в зависимости от ресурсов клиента.

- Премия управляющего напрямую зависит от полученной доходности

- Договор доверительного управления и инвестиционная декларация обеспечивают защиту инвестора от несанкционированных действий управляющего.

Отрицательные стороны индивидуального доверительного управления:

- Высокий барьер входа. Обычно такими услугами пользуются состоятельные частные инвесторы, крупные организации.

- Независимо от индивидуального подхода, инвестор не может непрерывно контролировать все операции управляющего.

- Редко можно вывести хотя бы часть средств, находящихся в ИДУ.

Для доверительного управления характерна близость отношений между двумя сторонами ДУ (непосредственно управляющий и инвесторучредитель). В результате такого тесного контакта исчезают факторы, ограничивающие инвестиционную и финансовую активную деятельность граждан. К таким факторам относятся:

- недоверие потенциальных инвесторов к подобным финансовым инструментам;

- неполнота информации, касающейся самой деятельности финансового рынка в целом и таких финансовых институтов, как управляющие компании, в частности.

Принципы доверительного управления:

1. Как правило, управляющий при управлении инвестиционным портфелем клиента может формировать сам портфель и осуществлять инвестиционные сделки с ценными бумагами.

2. Услуги доверительного управляющего должны быть оплачены в виде определенного процента.

3. Договоры доверительного управления являются срочными соглашениями, следовательно, отношения ДУ имеют временной характер.

4. Наличие лицензии ЦБ России подразу- 
мевает наличие профессиональных навыков и знаний у управляющих, следовательно, отношения ДУ имеют профессиональный характер.

5. Основная цель доверительного управления - получение дохода учредителями и доверительными управляющими.

На основе этих принципов можно выделить особенности ДУ и возможность их реализации в РФ в рамках функционирования современного рынка ценных бумаг [4].

1. Самостоятельность и ответственность доверительных управляющих.

Действия УК не могут быть одинаковыми для каждого инвестора. Также, в отличие от взаимодействия с брокером, учредитель не дает никаких прямых указаний по работе с определенным активом. Поэтому управляющий принимает самостоятельные решения, основываясь на портфеле каждого инвестора. Этому способствует и то, что инвестор-учредитель не контролирует действия управляющего в процессе распоряжения активами. Действия доверительного управляющего имеют определенные ограничения для вкладов и ПФИ. Так, запрещается проведения некоторых операций с данными активами и существует обязанность предоставления отчетности клиентам о состоянии его инвестиционного портфеля не реже, чем один раз в квартал.

2. Оплата услуг ДУ.

Поскольку деятельность доверительного управляющего является самостоятельной, и отсутствует контроль за его действиями со стороны инвестора, то существует риск злоупотребления полномочиями и оппортунистического поведения со стороны управляющего. Поэтому оплата услуг ДУ служит неким рычагом, который гарантирует честность со стороны управляющего, который должен соблюдать права и интересы инвесторов. При этом, максимальный размер оплаты услуг индивидуального управляющего не ограничивается законодательством РФ, в отличие от услуг коллективного управляющего.

3. Срочность ДУ.

Управляющий обязан соблюдать указанные временные рамки и в нужный момент возвращать инвестору переданные им в управление активы. Конкретные временные границы указаны в законодательстве РФ.

4. Договорный характер ДУ

Для соблюдения формализации договоры Ду должны иметь схожую структуру, поэтому в ГК РФ закреплены минимальные реквизиты договоров доверительного управления, а в подзакон- ных актах Центробанка реквизиты дополняются. Таким образом, существует контроль со стороны ЦБ РФ за соблюдением договоров.

5. Материальная выгода ДУ.

Поскольку результат деятельности доверительного управляющего важен для каждой из сторон (инвестор получает прибыль, а у управляющего от качества сделки зависит вознаграждение), то в российской юрисдикции отсутствуют обязательства по обеспечению минимального и фиксированного уровня дохода. Однако с другой стороны, именно это может породить условия для оппортунистического поведения управляющего, что отразится и на инвесторе, который может неэффективно распоряжаться своими активами.

6. Функционирование в условиях конкурентного рынка.

Конкуренция между субъектами российского рынка доверительного управления является достаточно интенсивной. В этих условиях для того, чтобы привлечь новых инвесторов к торгам, финансовым посредникам стало необходимо постоянно сокращать комиссионные за предоставление услуг и обслуживание. Между тем, получать прибыль за счет комиссионных стало практически невозможно, поскольку комиссия носит демпинговый характер. Эти моменты обострили конкуренцию между такими участниками фондового рынка, как управляющие компании и коммерческие банки [5].

Управляющие компании более доступны клиенту, нежели коммерческие банки. Это связано со следующими особенностями:

- предоставление диверсифицированных инвестиционных услуг;

- глубокая специализация;

- высокая мобильность помогает УК быстро приспосабливаться к изменяющимся условиям финансового рынка.

Все это делает компании по доверительному управлению наиболее привлекательными для инвесторов-учредителей. Однако, по сравнению с коммерческими банками УК уделяет меньше внимания вопросам обеспечения качества предоставляемых услуг.

В 2019 г. рынок ДУ и коллективных инвестиций в РФ увеличился на $18 \%$ и достиг 8,1 трлн. руб. В 2020 г. рост составил 11\% и достиг 9,1 трлн. руб. У розничных клиентов наиболее востребованными являются ДУ ИИС, ОПИФы акций и БПИФы разных направлений инвестирования (Табл. 1). 
Таблица 1. ТОП-15 управляющих компаний РФ в 2020 г.

\begin{tabular}{|l|c|c|}
\hline \multicolumn{1}{|c|}{ Управляющие компании } & $\begin{array}{c}\text { Объем активов под } \\
\text { управлением, трлн. руб. }\end{array}$ & Доля на рынке, \% \\
\hline 1.Компании бизнеса «ВТБ Капитал управление активами» & 1,28 & 14,1 \\
\hline 2.Компании бизнеса Сбер Управление активами» & 1,20 & 9,2 \\
\hline 3.Группа УК «Регион» & 0,87 & 8,6 \\
\hline 4.Компании бизнеса управления активами «Открытие» & 0,78 & 7,3 \\
\hline 5.»Альфа-Капитал» & 0,67 & 52,7 \\
\hline Итого: ТОП-5 & 4,80 & 6,8 \\
\hline 6. «Газпромбанк - Управление активами» & 0,62 & 5,8 \\
\hline 7. «Лидер» & 0,52 & 5,2 \\
\hline 8. «ТКБ Инвестмент Партнерс» & 0,47 & 4,0 \\
\hline 9. «Прогрессивные инвестиционные идеи» & 0,36 & 3,8 \\
\hline 10. «Трансфингрупп» & 0,35 & 2,5 \\
\hline 11. «Ай Кью Джи Управление активами» & 0,23 & 2,0 \\
\hline 12. «Система капитал» & 0,18 & 1,5 \\
\hline 13. «РСХБ Управление активами» & 0,14 & 1,3 \\
\hline 14. «Райффайзен Капитал» & 0,12 & 1,2 \\
\hline 15. «Ингосстрах-Инвестиции» & 0,11 & 86,8 \\
\hline Итого: ТОП-15 & 7,90 & 100 \\
\hline Все УК & 9,1 & \\
\hline
\end{tabular}

Источник: составлено автором на основе данных [6]

На долю 15 ведущих УК в 2020 пришлось $86,8 \%$ активов всего рынка по сравнению с $84.4 \%$ в 2019 г. На долю ТОП-5 УК в 2019 г. приходилось $50,7 \%$, а в 2020 г - 52.7\%, что свидетельствует о росте концентрации данного рынка. Состав ТОП-5 УК в 2020 г. несколько изменился. На первое место по объему активов вышли компании бизнеса «ВТБ Капитал управление инвестициями», опередив лидера 2019 г. - «Сбер управление активами». Впервые на 5 место вышел «АльфаКапитал», вытеснив «Газпромбанк».
Основными источниками роста активов в ДУ являются средства частных инвесторов, вложенные в УК «Альфа-Капитал», «Сбер Управление активами» и «Открытие». Высокий интерес к этим УК вызывается низким минимальным размером начального капитала для реализации стандартных стратегий инвестирования, возможностями самостоятельного выбора инвестиционных стратегий и использования для инвестирования индивидуального инвестиционного счета [7].

\section{Библиографический список}

1. Недорезова Е.С., Ермолаев К. Н. Проблемы и перспективы развития индивидуального инвестирования в Самарской области. //Экономические науки, 2020, № 8(189). С. 12-17.

2. Вишневер В.Я., Самотаева В.С. Портфельное инвестирование в условиях российского фондового рынка. // Наука XXI века: актуальные направления развития: сборник научных статей IX Международной научнопрактической конференции, 15 сентября 2020 года / редколлегия: С.И.Ашмарина, А.В.Павлова (ответственные редакторы) [и др.]; Самарский государственный экономический университет.- Самара: Издво СГЭУ, 2020.- Вып. 2, ч. 2.- С. 54-57.; Вишневер В.Я., Барсукова А. И. Конкурентные преимущества АО «ФИНАМ» на российском рынке управляющих компаний // Российская наука: актуальные исследования и разработки: сб. науч. ст. VIII Всерос. науч.-практ. конф., 10 окт. 2019 г.: в 2 ч. / [редкол.: С. И. Ашмарина, А. В.Павлова (отв. ред.) и др.].- Ч. 1.- Самара: Изд-во Самар. гос. экон. ун-та, 2019. - С. 509-511. 
3. Вишневер В.Я., Кусков В.М., Недорезова Е. С. Тенденции и перспективы развития паевых инвестиционных фондов в системе коллективного инвестирования // Экономические науки, 2019, № 9(173). С. 19-24.; Ермолаев К.Н., Недорезова Е.С. Компаративистский подход к анализу ПИФов в системе коллективного инвестирования. //Экономические науки, 2020, № 1(182). С. 13-16.; Коновалова М. Е., Недорезова Е. С. Особенности функционирования паевых инвестиционных фондов в системе коллективного инвестирования. //Экономические науки, 2020, № 1(182). С. 17-20.

4. Люц E. В. Перспективы использования комплексного подхода к доверительному управлению на рынке ценных бумаг //Вестник Самарского государственного экономического университета, 2018, № 5(163). С. 57-64.

5. Коновалова М.Е., Кузьмина О. Ю., Ляченков Ю.Н. Отличительные черты процесса инвестирования в условиях трансформации российской экономики. //Экономические науки, 2020, № 7(188). С. 7-12.

6. Предварительные итоги рынка доверительного управления в IV квартале 2020 года. // https://www.raexpert. ru/researches/ua/du_4q_2020pre/; Гайдаев В Триллионов прибыло. Активы под управление растут на рознице //Коммерсантъ. № 12 от 26.01.2021. С. 8.// https://www.kommersant.ru/doc/4662028; Обзор ключевых показателей профессиональных участников рынка ценных бумаг№ 3- III квартал 2020 года.// https://www. cbr.ru/analytics/rcb/review_rcb/

7. Анисимова E. В. Особенности современного рынка доверительного управления в России. //Наука, образование и культура, 2020, № 4(48). С. 9-13. 